\title{
A cultura da performatividade na organização do trabalho pedagógico: a formação matemática nos cadernos do Pacto Nacional pela Alfabetização na Idade Certa (Pnaic)
}

\author{
Patrícia de Faria Ferreira ${ }^{a}$ \\ Márcia Souza Fonseca ${ }^{a}$
}

\section{Resumo}

O presente trabalho analisa os impactos do Pacto Nacional pela Alfabetização na Idade Certa (Pnaic) na formação matemática de Professores Alfabetizadores e sua relação com a cultura da performatividade. Trata-se aqui da análise de um dos Cadernos de Alfabetização Matemática utilizados como instrumento auxiliar no processo de formação continuada de professores, o Caderno de Formação 1 - Organização do Trabalho Pedagógico. Para o tratamento com o caderno, utilizou-se de ferramentas analíticas inspiradas em Michel Foucault buscando, através dos enunciados, entender a produção de um novo jeito de ser professor. A análise permite indicar que a proposta do Pacto visa reformar a maneira de ser Professor Alfabetizador de Matemática, intensificando o trabalho, maximizando a performance e instrumentalizando a formação dos professores no sentido de renovar metodologias e recursos didáticos.

Palavras-chave: Pnaic. Política pública. Cadernos de alfabetização matemática. Cultura da performatividade.

\section{Introdução}

O presente trabalho analisa um dos Cadernos de Alfabetização Matemática utilizados pelo Pacto Nacional pela Alfabetização na Idade Certa - Pnaic - como instrumento auxiliar no processo de formação de Professores Orientadores de Estudo e Professores Alfabetizadores. O Caderno de Formação 1 - Organização

\footnotetext{
a Universidade Federal de Pelotas (UFPel). Pelotas, Rio Grande do Sul, Brasil.
} 
do Trabalho Pedagógico - faz parte de um conjunto de cadernos que objetivam subsidiar o debate relativo à formação continuada para os professores, ampliando discussões sobre alfabetização.

Para o tratamento com os enunciados do caderno utilizou-se de ferramentas analíticas de inspiração foucaultiana nas quais o autor relaciona o discurso à construção social e histórica que expressa contextos, sentimentos, relações de poder, enfim, à produção de realidades específicas.

Foucault (1996) propõe que os discursos formam os objetos aos quais se referem e que constituem práticas; e é através dos enunciados descritos no Caderno 1 que se busca compreender o discurso instituído pelo Pnaic que, adaptado a contextos singulares, vai produzindo novas práticas sociais, novas formas de subjetivação e uma nova cultura, a cultura da performatividade.

A divulgação dos resultados de avaliações externas e indicadores de qualidade da educação revelaram um quadro preocupante no ciclo de alfabetização nas escolas brasileiras.

Na busca de reverter estatísticas, o Ministério da Educação (MEC) lançou, em 2012, o Pnaic.

\section{O Pnaic e a alfabetização matemática}

O programa para formação continuada de professores do Ciclo de Alfabetização, Pnaic, é um compromisso formal entre o governo federal, estados, municípios e distrito federal que objetiva alfabetizar todas as crianças das escolas públicas brasileiras até os oito anos de idade. As ações do Pacto para os entes governamentais que formalizaram o compromisso são as seguintes:

I - Pela integração e estruturação, a partir do eixo Formação Continuada de Professores Alfabetizadores, de ações, de materiais e referências curriculares e pedagógicas do MEC que contribuam para a alfabetização e o letramento;

II - Pelo compartilhamento da gestão do programa entre a União, Estados, Distrito Federal e Municípios;

III - Pela garantia dos direitos de aprendizagem e desenvolvimento, a serem aferidos nas avaliações externas anuais (BRASIL, 2012, p. 22). 
Tais ações têm como objetivos:

I - Garantir que todos os estudantes dos sistemas públicos de ensino estejam alfabetizados, em Língua Portuguesa e em Matemática, até o final do $3^{\circ}$ ano do Ensino Fundamental;

II - Reduzir a distorção idade-série na Educação Básica;

III - Melhorar o Índice de Desenvolvimento da Educação Básica (IDEB);

IV - Contribuir para o aperfeiçoamento da formação de professores alfabetizadores;

$\mathrm{V}$-Construir propostas para a definição dos direitos de aprendizagem e desenvolvimento das crianças nos três primeiros anos do Ensino Fundamental (BRASIL, 2012, p. 23).

O Programa apresenta quatro eixos de atuação: 1) Formação continuada presencial para Professores Alfabetizadores e seus Orientadores de Estudo; 2) Materiais didáticos, obras literárias, obras de apoio pedagógico, jogos e tecnologias educacionais; 3) Avaliações sistemáticas e 4) Gestão, controle, e mobilização social.

A formação continuada do Pacto tem como referência a Política Nacional de Formação de Profissionais do Magistério da Educação Básica, instituída no Decreto $n^{\circ} 6.755 / 2009$. O programa envolve os professores de $1^{\circ}$ a $3^{\circ}$ anos de escolas públicas, docentes de universidades e secretarias municipais e estaduais de educação em todo o Brasil. No ano de 2013, focou os estudos na área de Linguagem e, em 2014, direcionou a formação para a área da Matemática.

A partir do material estudado e produzido nas formações, os Professores Alfabetizadores planejam e colocam em prática, com seus alunos, as propostas pedagógicas do Pacto. O planejamento do Professor Alfabetizador precisa contemplar e garantir os Direitos de Aprendizagem e as competências e habilidades referentes a cada conteúdo, que serão desenvolvidas segundo o documento da Secretaria de Educação Básica, nomeado Elementos Conceituais e Metodológicos Para a Definição dos Direitos de Aprendizagem e Desenvolvimento do Ciclo de Alfabetização.

O monitoramento das práticas dos professores é feito pelo Orientador de Estudos, que deve se manter informado quanto às ações do Pacto. O Professor Alfabetizador 
precisa registrar suas práticas e manter atualizado o Sistema Integrado de Monitoramento Execução e Controle (Simec). Simec é um site do Ministério da Educação no qual estão reunidos todos os programas e políticas públicas educacionais implementadas pelo governo. Nele, o profissional cadastrado gerencia suas atividades, podendo verificar o andamento de seu trabalho, das avaliações e do pagamento da bolsa de estudos. Para ter direito ao recebimento da bolsa, os professores devem participar de todas as formações, realizar todas as atividades propostas, ter boa avaliação e também manter atualizado o registro das ações no Simec. Essa não é uma tarefa só dos Alfabetizadores, os Orientadores de Estudo também precisam registrar suas práticas e fazer relatório descritivo-reflexivo de cada encontro para os seus Formadores. O planejamento é supervisionado e deve ser enviado ao Formador antes de ser executado com os Professores Alfabetizadores. Orientadores de Estudo e Formadores também têm suas práticas avaliadas pela equipe da Instituição de Ensino Superior e acompanhadas pelo Simec.

O Pacto é um programa de formação continuada que pretende melhorar o desempenho dos Professores Alfabetizadores para que estes consigam alfabetizar todas as crianças até os oito anos de idade, atendendo as metas do Plano Nacional da Educação e a elevação do Índice de Desenvolvimento da Educação Básica. A política de formação matemática do Pnaic traz novos elementos ao trabalho docente, sua perspectiva deve ser compreendida dentro das novas concepções para as políticas de formação continuada de professores, que serão tratadas a seguir.

\section{A cultura da performatividade}

O Índice de Desenvolvimento da Educação Básica (IDEB) está entre os principais motivos para as reformas consideradas necessárias para a reestruturação do sistema de ensino. As políticas públicas para a educação no Brasil pretendem atingir melhores resultados nas avaliações externas e, consequentemente, a elevação dos índices no Ciclo de Alfabetização. Esses são alguns dos objetivos do Pnaic, como foi citado anteriormente.

Essa ação do governo federal em busca da qualificação dos professores e consequentemente da alfabetização possui parâmetros e orientações muito semelhantes às sugeridas pela Organização de Cooperação e Desenvolvimento Econômico - OCDE - que tem o Brasil como parceiro e, futuramente, possível membro.

Em uma análise dos documentos elaborados pela OCDE, Maués (2011) propõe uma reflexão sobre a influência dessa instituição nas políticas públicas dos países-membros e parceiros. É destacado pela autora que a OCDE cria regras 
e normas que influenciam fortemente países que necessitam de benefícios econômicos, passando então a regular a educação dentro da lógica do mercado.

A área da educação é colocada como essencial ao desenvolvimento econômico e o professor desempenha papel fundamental na qualificação do ensino. A OCDE faz orientações de como os governos devem agir para garantir um bom desempenho dos professores, apresentando as funções essenciais a um profissional comprometido e sugerindo como devem ser os planos de carreira, formação inicial e continuada, avaliação e outras ações relativas à vida profissional dos educadores. Sugere, ainda, um perfil do que seria o "adequado" ao profissional que desempenha suas atividades na chamada sociedade do conhecimento. Dentre as ações do Pacto e as orientações para a formação de docentes sugeridas pela OCDE, identificam-se algumas aproximações:

- Formação de professores - políticas de formação como principal solução para a melhoria dos indicadores de qualidade. A OCDE afirma que:

A qualidade do corpo docente é um fator de primeiro plano, quando um país, qualquer que seja, aspira a excelência de seu sistema educacional. Os professores constituem o centro do sistema escolar, e as pesquisas mais diversas confirmam quanto a qualidade dos professores conta na aquisição dos alunos. É por isso que os poderes públicos levam tão a sério a melhoria da qualidade dos professores, para assegurar que todos os alunos se beneficiem de um bom ensino (La qualité du personnel enseignant, 2004 apud MAUÉS, 2011, p. 77).

Dentre os quatro eixos do Pacto, o principal é a formação continuada de professores alfabetizadores (BRASIL, 2014a).

- Concepção de formação - Tanto as perspectivas do Pacto quanto da OCDE encaminham para uma formação mais técnica e menos relacionada aos fundamentos teóricos da educação. Daí pode resultar que conceitos como contexto, por exemplo, sejam alijados da cultura e se tornem frágeis e generalizantes (PIMENTA, 2014), conforme indicam algumas propostas descritas nos cadernos de formação.

As pesquisas realizadas pela OCDE indicam que tanto a formação inicial como a continuada são pouco qualificadas, mas importantes, 
[...] devendo ambas possibilitar uma sólida formação teórica e prática da especialidade do professor (leitura, matemática, história), e os conhecimentos e as competências pedagógicas necessárias para transmitir seu saber de forma bem didática, motivar os alunos, avaliar o progresso da aprendizagem e adaptar o ensino às necessidades de cada aluno. Como se vê, não há uma preocupação maior com os conhecimentos relativos a disciplinas da área das Ciências Humanas, como Filosofia, Sociologia, Antropologia, Psicologia, que podem dar a sustentação necessária para que o professor situe os conhecimentos ministrados à realidade que o circunda de mais perto e no mundo como um todo (MAUÉS, 2011, p. 78).

O Pacto também prioriza as competências pedagógicas que, conforme descrito nos cadernos de Alfabetização Matemática, têm como objetivo "proporcionar aos professores um repertório de saberes que possibilitem desenvolver práticas de ensino de Matemática que favoreçam as aprendizagens dos alunos" (BRASIL, 2014b, Caderno 1, p. 5).

- Avaliação-É necessário avaliar o trabalho docente através de monitoramentos e também a partir do resultado dos alunos. Nas recomendações da OCDE essa é uma das mais importantes medidas.

A necessidade de realizar avaliação periódica dos professores deve ser considerada com parte integrante da rotina desse profissional. O papel da avaliação formativa é exaltado, mas ao mesmo tempo é sinalizado que a avaliação pode servir para recompensar os profissionais por excelência dos resultados de seu trabalho, que é mensurado, entre outros fatores, pelo desempenho dos alunos (MAUÉS, 2011, p. 82).

A avaliação também é contemplada nas ações do Pnaic,

I - Avaliação do nível de alfabetização, mediante a aplicação anual da Provinha Brasil aos estudantes das escolas participantes, pelas próprias redes de ensino, no início e no final do $2^{\circ}$ ano do Ensino Fundamental;

II - Disponibilização pelo INEP, para as redes públicas, de sistema informatizado para coleta e tratamento dos resultados da Provinha Brasil; 
III - Análise amostral, pelo INEP, dos resultados registrados após a aplicação da Provinha Brasil, no final do $2^{\circ}$ ano;

IV - Avaliação externa universal do nível de alfabetização ao final do $3^{\circ}$ ano do Ensino Fundamental, aplicada pelo INEP (BRASIL, 2012, p. 23).

Os professores vinculados ao Pacto são avaliados segundo os critérios da frequência e atividades realizadas e precisam atingir a nota mínima $(7,0)$ para o recebimento da bolsa.

- Inovações no trabalho do professor - As transformações da sociedade tencionam mudanças na escola e esta é uma das preocupações da OCDE.

Afinal, as exigências que a partir dessas inovações devem ser introduzidas na escola vão alterar substancialmente o papel e as funções/trabalho do professor. Em relação aos alunos o professor deverá estar envolvido com a aprendizagem, com o atendimento às diferenças individuais e voltado para que o processo de ensino tenha uma avaliação formativa e somativa. Já em relação a sala de aula, o professor da "sociedade do conhecimento" deverá estar voltado para turmas multiculturais, aos conhecimentos transversais e as classes com alunos com necessidades especiais. As mudanças também atingem a escola. Em relação a esta, o professor tem que estar preparado para trabalhar e planejar em equipe, aplicar instrumentos de avaliação externa, saber utilizar tecnologias de informação e comunicação, participar de projetos de cooperação internacional, além de participar da gestão e das tomadas de decisão. Mas as funções não terminam aí, também o professor deve estar preparado para trabalhar com os pais e a comunidade localizada no entorno da escola. Para tanto, deve ser capaz de aconselhar os pais de maneira profissional e estabelecer parcerias para a realização de ações com a comunidade local (MAUÉS, 2011, p. 82).

Nos cadernos de Alfabetização Matemática do Pnaic, especialmente no Caderno 1 - Organização do Trabalho Pedagógico - há orientações para mudanças no trabalho e aumento de atribuições para o professor. Essas orientações/recomendações são tratadas mais detalhadamente no item de análise do Caderno. 
Maués (2011), em sua pesquisa sobre a política de formação de professores recomendada pela OCDE, afirma que:

As políticas de formação expressas nos documentos da OCDE analisadas neste trabalho têm característica de imprimirem regulação pós-burocrática em função da valorização instrumental, da ênfase na eficácia e na performance que são inerentes às concepções apresentadas e pela adoção de formas de controle que incidem sobre resultados, com um discurso de autonomia do processo (p. 82).

É a partir da assertiva acima, "ênfase na eficácia e na performance que são inerentes às concepções apresentadas" (MAUÉS, 2011, p. 82), que se encaminha a discussão para a relação entre as atuais políticas públicas de formação de professores e a cultura da performatividade.

Através de estudos de Ball (2012) sobre reformas na educação e a busca pela performatividade, é possível analisar como as reformas educacionais estão mudando as escolas, as relações entre professores e, principalmente, o ser professor. Para que possa cumprir com as novas atribuições, o professor precisa qualificar e aumentar seu desempenho e sua performance, conceituada pelo autor como:

Uma tecnologia, uma cultura e um modo de regulação que emprega avaliações, comparações e demonstrações como meios de controle, desgaste e mudança. As performances de indivíduos ou organizações servem como medidas de produtividade ou resultado, demonstrações de "qualidade", ou "momentos" de promoção ou inspeção (2012, p. 37).

A cultura da performatividade permeia as ações das reformas e se sobrepõe na constituição do que significa ser professor (Ball 2002), visando à formação, atualização e reforma não apenas das práticas, mas da identidade docente, assim conceituada por Garcia (2010):

[...] um conjunto de características, experiências e posições de sujeito atribuídas (e autoatribuídas) por diferentes discursos e agentes sociais aos docentes no exercício de suas funções, em instituições educacionais mais ou menos complexas e burocráticas [...]. A identidade docente é, ao mesmo tempo, um processo de identificação e diferenciação, não fixo e provisório, que resulta de negociações de ordem simbólica que os professores realizam em 
meio a um conjunto de variáveis como suas biografias, as relações e condições de trabalho, a história e a cultura que caracteriza a docência enquanto atividade profissional, e representações colocadas em circulação por discursos que disputam os modos de ser e agir dos docentes no exercício do ensino e do trabalho docente (p. 15).

As políticas educacionais, mais especificamente as direcionadas à formação continuada, estão transformando o trabalho e a identidade docente. Para Costa (2006), as identidades docentes vêm sendo construídas por discursos que exaltam novas competências e habilidades, e é através de discursos oficiais que o Estado manipula as identidades de modo sutil, garantindo as mudanças pretendidas.

Os discursos que anseiam por mudança agem e alteram a atuação do professor, levando-o a crer que sem o seu máximo esforço e dedicação, as mudanças e melhorias esperadas por todos não serão possíveis. Nestes discursos,

[...] discutem-se a desprofissionalização e a intensificação do trabalho dos professores e a emergência de uma identidade centrada no domínio de competências muito específicas relativas à instrução na performatividade e na autorresponsabilização pelo desenvolvimento profissional (GARCIA, 2010, p. 16).

As novas políticas públicas passam pelas reformas da educação e aproximam-se da cultura da performatividade. Novas palavras, novas metodologias, novos recursos, novos ambientes para a aula, nova forma de avaliação, novos objetivos, novas propostas pedagógicas. Para colocar tanta novidade em funcionamento, é preciso um novo profissional, atento às demandas atuais e com muitas outras atribuições. Os estudos sobre reforma e performatividade de Ball buscam entender as mudanças provocadas nas relações e subjetividades.

Novos papéis e subjectividades são criados conforme os professores são "re-trabalhados" como produtores/proporcionadores, empreendedores educacionais e gestores e são sujeitos a avaliações/apreciações regulares, a revisões e comparações de seu desempenho. Novas formas de disciplina são colocadas pela competição, eficiência e produtividade (BALL, 2002, p. 7).

Em um contexto de performatividade, a lógica da economia e do mercado é predominante, e isso se reflete nas relações dos professores e nas suas práticas. Se a ordem é inovar e aumentar o desempenho, cada professor responsabiliza-se 
por deixar seu currículo mais atraente. Mas isso também não é suficiente para que a performance seja reconhecida, é preciso investir em uma postura e também em práticas afinadas ao novo discurso. A eficácia precisa mostrar-se em resultados e esses resultados estão associados às avaliações externas e em larga escala. Índices baseados nessas avaliações têm legitimidade para indicar a qualidade, bem como a busca pela performance.

As reformas da educação trazem consigo uma série de novas propostas para a gestão, para o ensino, para o ambiente escolar, para a relação com a comunidade e, especialmente, para a postura do professor. A fim de que as novas ideias entrem em funcionamento, é preciso que se abandonem as antigas e, para isso, é necessário acreditar que estas já não são adequadas, estão desatualizadas e, de certa forma, podem até prejudicar o processo de aprendizagem, limitando a capacidade dos sujeitos. Para Ball (2012):

Um novo tipo de professor e novos tipos de conhecimento são "convocados" pela reforma educacional - um professor que pode maximizar a sua performance, que pode descartar princípios irrelevantes, ou compromissos sociais fora de moda, para quem a excelência e a melhoria são o motor propulsor de sua prática (p. 44).

Paralelamente às reformas e implantação de políticas públicas de formação docente, surgem novos programas, objetivos são revistos e repensados e precisam estar alinhados às novas expectativas colocadas para a educação - novas (ou renovadas) metodologias que aparentemente são muito mais eficazes que aquelas que até então eram a referência.

Assim, as reformas chegam às escolas trazendo a ideia de mudança e inovação e discussões e reflexões tornam-se o centro das ações: como adequar a escola às novas demandas? Como adequar-se ao novo perfil? Essas inquietações, mais do que vistas, são sentidas pelos professores. Esse é um dos objetivos dos atuais programas de formação de professores em andamento no país. Outro objetivo é que o professor, influenciado pelo contexto das reformas e políticas de formação, perceba a necessidade de desenvolver outras habilidades e competências que antes não faziam parte de seu trabalho.

A educação tem se mostrado uma área carente de políticas públicas comprometidas com a qualidade, portanto, reformas chegam como promessas de melhoria e conquistam seguidores que, subjetivados pela ideia de mudança, não percebem que o compromisso é principalmente com a melhoria de índices. Esses são grande 
parte dos profissionais que irão fazer de tudo para melhorar sua performance. "Com efeito, nós nos criamos na medida da informação que construímos e transmitimos sobre nós mesmos. Nós nos articulamos dentro desses jogos representacionais de competição, intensificação e qualidade" (BALL, 2010, p. 39).

Ampliam-se os principais objetivos das reformas sobre todas as esferas da educação e suas forças aumentam à medida que profissionais buscam melhorar sua performance.

A competitividade e o individualismo alteram as relações dentro da escola e também modificam a imagem que cada professor tem de si. Essa situação gera diversos sentimentos, de um lado a empolgação pelo triunfo pessoal e, de outro, os sentimentos de culpa, inferioridade, inveja, instabilidade e, também, "dúvidas constantes acerca de que tipo de julgamento/avaliação pode estar em jogo num dado momento, em qualquer momento, significam que toda e qualquer comparação e exigência a desempenharem têm de ser cuidada com interesse e eficiência" (BALL, 2002, p. 10).

Os efeitos da cultura da performatividade atingem também os professores que não concordaram com as políticas e mudanças e que não estão dispostos a romper com suas práticas. O trabalho para o aumento do desempenho e da produtividade é rejeitado e muitos desses profissionais sofrem pressões que levam ao adoecimento e/ou afastamento do trabalho. Ball chama esse processo de uma espécie de esquizofrenia de valores, quando o compromisso e a experiência na prática têm que ser sacrificadas em favor da impressão e da performance (Ball, 2012, p. 43).

Nesse contexto, aprender não é mais o centro do processo educativo, pois não é suficiente ensinar e avaliar o aluno, é preciso demonstrar que ensinou e, principalmente, ir além dos objetivos que estavam planejados.

Algumas práticas e teorias pedagógicas passam a ter maior visibilidade do que outras, posturas profissionais são eleitas como adequadas e salas de aula são classificadas quanto ao potencial educativo que podem ofertar. Essa situação faz com que muitos professores se sintam inseguros, pois suas experiências e suas práticas já não são válidas, não têm lugar. A autenticidade é substituída pela performance, como nos propõe Ball.

Quando a autenticidade está baseada no valor da reflexão e na possibilidade sempre presente da indecisão - não que isso necessariamente sempre tenha acontecido na prática - mas uma vez 
que as possibilidades de reflexão moral, de diálogo e de indecisão são erradicadas, as possibilidades de profissionalização então estão, na verdade, erradicadas. Desejo continuar argumentando que esta erradicação é conseguida, trazida para fora, pelos efeitos combinados das tecnologias da performatividade e do gerencialismo, que juntas, perfeita e extremamente, representam a busca modernista da ordem, da transparência, e da classificação (BALL, 2012, p. 35).

O autor diferencia o profissional autêntico do profissional pós-reforma, afirmando que estes são "exogenamente gerados, seguidores de regras, e, que eles traduzem o profissionalismo numa forma de performance onde o que conta como prática profissional depende do satisfazer às decisões fixas impostas externamente" (BALL, 2012, p. 36).

E não é só sobre os professores que age a cultura da performatividade, as instituições educacionais também devem demonstrar todo seu potencial.

A propaganda não é mais só para as instituições particulares que possuem uma relação financeira com as famílias e, portanto, precisam apresentar a qualidade dos serviços prestados. Estão expostas ao ranqueamento e às premiações as instituições públicas de ensino, que frequentemente compartilham nas redes sociais imagens e vídeos de projetos e atividades de sucesso. Também usam documentos descritivos contendo objetivos, metas, estratégias e planos de ação, entre outros instrumentos que "podem desdobrar táticas discursivas para transmitir ordem e coerência, consenso e dinamismo, compreensibilidade e autoavaliação crítica, ou, para outros públicos, um personalismo sintético, uma instituição que se importa" (BALL, 2010, p. 48).

Mas toda essa nova forma de ser escola e de ser professor não se restringe a um desejo da comunidade, tem a ver com um projeto mais amplo de sociedade, que mobiliza outros setores e outros atores sociais, locais e globais.

Os objetivos da reforma da educação estão em sintonia com as orientações de instituições econômicas internacionais e vão bem além dos que são apresentados à sociedade.

Significativamente, então, as tecnologias políticas da reforma do setor público não são simplesmente veículos para a mudança técnica e estrutural das organizações, mas sim mecanismos para reformar os profissionais do setor público, tais como professores, para 
mudar o que significa ser professor, assistente social ou enfermeiro [...]. Dentro das políticas, tecnologias de reforma estão inseridas e fornecem novas identidades, novas formas de interação e novos valores (BALL, 2012, p. 39).

As políticas públicas educacionais deste tempo são pautadas pela lógica do mercado e pela cultura da performatividade. Professores são interpelados cada vez mais por discursos aliados aos objetivos dessas políticas, que ao descreverem, constituem novos profissionais, novas escolas e consequentemente uma nova cultura. Ball centra seus estudos nas reformas educacionais e suas consequências na cultura da performatividade e tais ferramentas constituíram o solo teórico sobre o qual se analisou a Formação Matemática no Pacto Nacional pela Alfabetização na Idade Certa.

\section{A organização do trabalho pedagógico e o ser professor}

Para a formação continuada de professores em Alfabetização Matemática, o MEC editou 12 Cadernos temáticos. O Caderno de Apresentação é uma introdução à Alfabetização Matemática e ao desenvolvimento do trabalho; o Caderno 1 trata da Organização do Trabalho Pedagógico; o Caderno 2, da Quantificação, Registros e Agrupamentos; o Caderno 3 problematiza a Construção do Sistema de Numeração Decimal; o Caderno 4, das Operações na Resolução de Problemas; o 5, da Geometria; o Caderno 6 das Grandezas e Medidas; o 7, da Educação Estatística e o Caderno 8, dos Saberes Matemáticos e Outros Campos do Saber. Os Cadernos complementares tratam da Educação Matemática do Campo, Jogos na Alfabetização Matemática, Educação Inclusiva e Encartes com o material a ser utilizado.

Todos os Cadernos são divididos nas seções: Iniciando a Conversa, Aprofundando o Tema, Compartilhando, Para Saber Mais, Sugestões de Atividades para os Encontros em Grupos e Atividades para Casa e Escola que, de forma geral, apresentam textos, dicas e relatos direcionados a orientar o trabalho e a postura do professor. No caderno analisado, Organização do Trabalho Pedagógico, é possível identificar o perfil adequado de um bom Professor Alfabetizador de Matemática, segundo o Pnaic.

Na primeira página, a seção Iniciando a Conversa apresenta os objetivos do Caderno:

Caracterizar a comunidade de aprendizagem da sala de aula com vistas à Alfabetização Matemática de todos os alunos; destacar a 
intencionalidade pedagógica como elemento essencial no processo de alfabetização; apontar possibilidades para a organização do trabalho pedagógico e compartilhar vivências de professores que buscam garantir os Direitos de Aprendizagem de Matemática de todos os alunos (BRASIL, 2014b, p. 5).

Para apresentar a proposta do Pacto quanto à Organização do Trabalho Pedagógico e às estratégias para atingir os objetivos descritos acima, o texto será dividido em três itens: planejamento, formação complementar e estratégias de sala de aula.

\subsection{Quanto ao planejamento}

Na seção Aprofundando o Tema estão os primeiros textos do Caderno, que tratam sobre diferentes formas de planejamento, planejamento anual, planejamento durante o período letivo, planejamento semanal e relatos de experiência. São destacadas as funções de cada planejamento e as ações necessárias do professor para elaborá-los. Em relação à seleção de conteúdos anuais, a orientação é que:

Esses conteúdos precisam ser discutidos e escolhidos, por exemplo, em função do material do pacto, do livro didático enviado pelo PNLD, das obras complementares da escola, dos livros de literatura infantil, dos projetos da escola, das diretrizes curriculares, das matrizes de avaliações em larga escala, de revistas especializadas e de outros recursos (BRASIL, 2014b, p. 8).

Grande parte dos materiais citados como exemplo de possibilidade de consulta para seleção dos conteúdos são produzidos pelo programa ou possuem objetivos e metodologias semelhantes. Segundo a legislação (LDB n ${ }^{\circ}$ 9.394/96 - BRASIL, 1996), toda seleção de conteúdos deve considerar as diretrizes curriculares e os Projetos Político-Pedagógicos da escola, mas, pela citação acima, é possível perceber que as matrizes de avaliação em larga escala estão no mesmo patamar de referência que a legislação. Apesar de o texto tratar sobre flexibilidade do planejamento, sabe-se que é necessário seguir as orientações, pois há um Simec que prevê sanções quando da não realização/participação nas tarefas do programa.

Ainda na primeira, o texto Organização da sala de aula: fazendo a aula acontecer indica como deve ser a organização do espaço físico da sala de aula e cita uma lista de materiais necessários para que o ambiente seja reconhecido como um espaço alfabetizador em Matemática com instrumentos, símbolos, objetos e imagens pertencentes ao campo da Matemática escolar e não escolar (BRASIL, 2014b). Imagens ilustrativas de organização desse material na sala de aula aparecem em 
várias páginas do caderno; também há indicação de como devem estar dispostas as carteiras, não sendo recomendado seu uso tradicional, em filas. Segundo o programa, as carteiras devem estar dispostas em duplas para favorecer a troca e a negociação de estratégias e significados na resolução de problemas, devendo ainda ser dispostas em grupos de 4 para os jogos e em formato $\mathrm{U}$, a fim de propiciar a discussão e a socialização (BRASIL, 2014b, p. 17). As descrições anteriores são prescrições para o trabalho do professor; as orientações são detalhadas, um passo-a-passo que desconsidera a função intelectual do professor que, nessa situação, torna-se apenas um profissional que necessita de um manual para planejar, selecionar materiais, executar o planejamento e organizar o espaço, contradizendo o Caderno de Apresentação, que coloca "o papel do professor como central, não cabendo confundi-lo com o de alguém que na sala de aula reproduzirá métodos e técnicas" (BRASIL, 2014c, p. 10). É importante destacar uma observação, à esquerda da página, em letras pequenas e de cor diferenciada do restante do texto:

Reconhecemos os problemas referentes à falta de tempo, espaço e materiais que o professor possui. No entanto ao indicarmos as necessidades para um trabalho pedagógico adequado, alertamos para a conquista desses aspectos junto às gestões das escolas e das redes municipais e estaduais (BRASIL, 2014b, p. 10).

Na citação acima, o professor recebe mais uma função, conquistar tempo, espaço e materiais. Atribuições da gestão escolar passam a ser também responsabilidade do educador, que cada vez mais é interpelado pela cultura da performatividade para aumentar seu desempenho. Mas o professor precisa saber mais...

\subsection{Quanto à formação complementar/saber mais}

Nesta seção, estão explícitas as formas "corretas" de planejar, propor atividades desafiadoras, organizar os alunos e os materiais em sala de aula, fazer intervenções, registrar, avaliar; enfim, todas as orientações necessárias para que o trabalho do professor tenha resultados satisfatórios, incluindo sugestões de livros, artigos, vídeos, entrevistas e sites para aprofundamento dos conhecimentos e novas experiências, através de leituras complementares.

Para complementar a formação, são indicadas algumas referências e só no Caderno analisado há indicação para leitura de seis artigos, três livros, dois vídeos e uma entrevista. Os relatos de experiências do caderno analisado propõem a postura adequada do professor para várias situações. Em um deles a professora finaliza com a seguinte conclusão: "Esse episódio reforça a importância de uma cultura 
social de sala de aula, na qual o professor esteja o tempo todo problematizando, isto é, colocando os alunos no movimento do pensamento, não lhes fornecendo respostas, mas novas questões" (BRASIL, 2014b, p. 31).

A fala da professora reforça a ideia de potencializar o trabalho, aumentar o desempenho e alcançar uma performance capaz de problematizar o tempo todo, como se isso fosse possível. Os professores cadastrados no Pacto são profissionais que desempenham suas funções em escolas públicas onde as salas de aula, geralmente, possuem elevado número de alunos, o que praticamente impossibilita essa ação.

Em outro relato, uma situação semelhante: "Esse tipo de mediação ocorre durante a própria aula, à medida que as duplas vão concluindo a atividade, o professor já analisa e faz as mediações e a imediata devolutiva" (BRASIL, 2014b, p. 33). Essa orientação é ilustrada no relato de um professor que utiliza uma tabela denominada Relatório de entrada múltipla. A tabela sugere uma situação-problema que, a partir da resposta de cada aluno, o professor cria e escreve de próprio punho uma problematização, devolve a tabela para o aluno resolvê-la e repete essa proposta até que se esgotem as possibilidades de produzir mais questionamentos e soluções. Essa é mais uma ação que é considerada imprescindível para o desenvolvimento do aluno e que necessita, para ser colocada em prática, que o professor maximize seu desempenho.

E não é só essa, outras várias atividades são indicadas:

Os diferentes registros produzidos pelos alunos precisam ser anotados numa ficha de observação para que possa ser feito o acompanhamento do progresso, diagnosticando os problemas e avaliando se as intervenções estão contribuindo ou não para o avanço das aprendizagens (BRASIL, 2014b, p. 36).

Anotar, acompanhar, diagnosticar, avaliar e intervir; cinco ações, algumas bem complexas, em apenas um parágrafo. Essa é uma característica marcante nos textos do Caderno, muitos verbos e ações acompanham a palavra professor, pois, no Pacto, sempre há possibilidade de ampliar o trabalho docente. Esse discurso, aliado à cultura da performatividade, é reafirmado nos relatos de experiências já citados, como no excerto abaixo:

A narrativa da professora Maria Ida exemplifica como é possível ampliar uma proposta do livro didático. Ela poderia simplesmente ter 
preenchido a tabela proposta no livro e dado continuidade, no entanto, aproveita a fala de uma aluna e desenvolve um amplo trabalho explorando as datas de aniversário dos alunos. Destaca-se que, quando a professora foi para o pátio da escola para desenhar o gráfico de pizza, [...]. Ela deu 'vida' ao gráfico (BRASIL, 2014b, p. 53).

Ao afirmar que os relatos de experiências do Caderno 1 estão em consonância com a cultura da performatividade, não se está julgando a experiência narrada, mas observando que, em todas elas, o destaque é para a ação a mais que o professor desempenhou.

É importante destacar o objetivo de o caderno "Compartilhar vivências de professores que buscam garantir os Direitos de Aprendizagem de Matemática de todos os alunos" (BRASIL, 2014b, p. 5). Ao ler esse objetivo, o alfabetizador cursista do Pacto é subjetivado pelas práticas e posturas apresentadas. O compartilhamento de experiências de professores que garantem o direito de todos aprenderem é um discurso que mobiliza o alfabetizador, pois a afirmação da aprendizagem assegura que essas são as práticas e perfis adequados.

Em síntese, o profissional com as características descritas é aquele que consegue garantir o Direito de Aprendizagem de todos os alunos. Na perspectiva de direcionar o olhar, a escolha e as ações do Professor Alfabetizador também estão as orientações para o trabalho em sala de aula.

\subsection{Quanto às estratégias de sala de aula}

São inúmeras as orientações sobre atividades relacionadas ao trabalho do professor, algumas descritas anteriormente, referentemente ao seu planejamento, intervenção e potencialização. O término das atividades é denominado fechamento da aula e é mais uma orientação, pois fazem parte desse momento a socialização e a entrega das produções. As orientações dão conta das variáveis, atividades coletivas e individuais; cada situação é contemplada com sugestões de como proceder e a postura adequada sempre é evidenciada: "É importante evitar dizer se está certo ou errado, mas solicitar a participação dos alunos na discussão, problematizando suas falas" (BRASIL, 2014b, p. 27). Na continuação do texto, mais orientações para que o trabalho com a Matemática seja eficaz: congresso matemático, síntese da aula, tarefa de casa, avaliação, progressão e continuidade das aprendizagens. Cabe destacar que inclusive a proposta para a tarefa de casa deve ser adequada às indicações do Pacto; para todas as atribuições do professor há uma maneira "mais correta" de agir. 


\begin{abstract}
A postura da professora Daniela em relação à negociação e ao respeito para com o texto de seus alunos se reflete na forma como eles também respeitam o texto dos colegas. Observa-se que a professora se reporta a situações vivenciadas por eles, reflete como os desdobramentos podem ocorrer de modo a promover avanço na aprendizagem Matemática de seus alunos (BRASIL, 2014b, Caderno 1, p. 64).
\end{abstract}

Essa é mais uma situação em que a garantia da aprendizagem está associada à postura da professora. Para que isso aconteça, algumas ações ganham destaque e reforçam a importância atribuída pelo Programa, é o caso do uso de registros pelo aluno e pelo professor, a resolução de problemas e o incentivo à discussão de estratégias e hipóteses. E, ao final do Caderno, na sessão Atividades para Casa e Escola, mais tarefas: ler os textos da sessão Aprofundando o Tema, fazer o perfil da turma e a partir dele retomar o Planejamento para apresentar ao grupo na próxima formação.

\title{
5 Algumas considerações
}

$\mathrm{O}$ texto procurou refletir sobre o professor que o Pacto quer formar e as principais características para ser um bom Professor Alfabetizador de Matemática.

A partir da análise do Caderno 1, pode-se indicar que o Pacto apresentou uma proposta de organização do trabalho pedagógico que visa a ampliar o desempenho do Professor Alfabetizador de Matemática. Ao longo do texto, a postura adequada do professor está relacionada diretamente com a garantia da aprendizagem.

Há orientações para todos os aspectos que envolvem a instituição escolar e o trabalho docente; planejamento, organização do espaço físico, lista de materiais a serem utilizados, correção das atividades, maneiras de intervir, de avaliar, de registrar e de propor o tema de casa, um chamamento à modernização e às inovações pedagógicas.

Os textos que compõem o caderno são prescritivos, recomendam o que fazer e como agir em cada situação, desconsiderando a capacidade e formação do professor. Embora pareça contraditório, ao mesmo tempo em que o Pacto confere a função de executor de tarefas ao alfabetizador, diminuindo seu trabalho intelectual, convoca-o a aumentar seu desempenho e a melhorar sua performance. $\mathrm{O}$ que se buscou mostrar foi que a perspectiva de formação de professores do Pnaic visa reformar a maneira de ser Professor Alfabetizador de Matemática, instrumentalizando seu trabalho com novas metodologias, novos recursos, novos jeitos de ser professor. 
Entende-se que o programa permitiu aos professores alfabetizadores estar em formação continuada na área da Alfabetização Matemática, trabalhar conhecimentos matemáticos e conhecer o trabalho de outros alfabetizadores, mas esse crescimento profissional foi direcionado para o aumento da produtividade: alfabetizar todas as crianças até os oito anos de idade. Os objetivos do programa estão em consonância com organizações que visam ao crescimento econômico, não há espaço para a pluralidade de ideias e perspectivas nas quais as experiências do alfabetizador cursista possam se somar.

Aponta-se a relação do Pnaic com a cultura da performatividade, com o olhar atento à formação e aos materiais ofertados aos professores, buscando compreender como o discurso do Pacto constitui professores, reforma as relações entre eles e instaura uma nova cultura. 


\section{The performativity culture in the organization of the pedagogical work: mathematics literacy in the PNAIC's booklet}

\section{ABSTRACT}

The present work aims to investigate the impacts of the National Pact for Literacy at the Right Age in the education in Mathematics of Literacy Teachers and its relation with the performativity culture. It consists here of an analysis of one of the Mathematics Literacy Booklet, used as a tool in the process of continuous training of teachers, the Teaching Booklet 1 - Organization of the Pedagogical Work. For the treatment with the booklet, analytical tools inspired in Foucault were used, aiming, through the instructions, to understand the production of a new way of teaching. The analysis enables indicating that the proposal of the Pact aims to reform the way the Mathematics Literacy Teacher is, intensifying the work, maximizing the performance, contributing for the teachers' education in order to renew methodologies and didactic resources.

Keywords: Pnaic. Public policy. Mathematics literacy booklet. Performativity culture.

\section{La cultura de la performatividad em la organización del trabajo pedagógico: la formación matemática en los manuales del Pnaic}

\section{RESUMEN}

El presente trabajo tiene como objetivo investigar los impactos del Pacto Nacional para la Alfabetización a la Edad Adecuada en la formación matemática de profesores de alfabetización y su relación con la cultura de la performatividad. Consiste aqui en un análisis de uno de los cuadernos de Alfabetización Matemática, que se utiliza como una herramienta en el proceso de la formación continua de los docentes, el Manual de Enseñanza 1 - Organización del trabajo pedagógico. Para el tratamiento con el cuaderno, se utilizaron herramientas de análisis inspiradas en Foucault, con el objetivo de, a través de las instrucciones, entender la producción de una nueva forma de ser profesor. El análisis indica que la propuesta del Pacto tiene como objetivo reformar la forma de ser profesor alfabetizador de matemáticas, intensificando el trabajo, maximizando el rendimiento, lo que contribuye a la instrumentalización de los profesores en el sentido de renovar metodologías y recursos didácticos.

Palabras clave: Pnaic. Política pública. Cuadernos de alfabetización matemática. Cultura de la performatividad. 


\section{Referências}

BALL, S. J. Performatividades e fabricações na economia educacional: rumo a sociedade performativa. Educação \& Realidade, v. 35, n. 2, p. 37-55, maio/ago. 2010.

. Reforma educacional como barbárie social: economismo e o fim da autenticidade. Práxis Educativa, v.7, n.1, p. 33-52, jan./jun. 2012. https://doi.org/10.5212/práxis\%20educativa.v7i1.4003

. Reformar escolas/reformar professores e os terrores da performatividade. Revista Portuguesa de Educação, v. 15, n. 2, p. 3-23, 2002.

BRASIL. Lei No 9.394, de 20 de dezembro de 1996. Estabelece as diretrizes e bases da educação nacional. Diário Oficial da União, 23 dez. 1996.

. Portaria $n^{\circ} 867$, de 4 de julho de 2012. Institui o Pacto Nacional pela Alfabetização na Idade Certa e as ações do Pacto e define suas diretrizes gerais. Diário Oficial da União, 5 jul. 2012.

. Ministério da Educação. Secretaria de Educação Básica. Pacto nacional pela alfabetização na idade certa: apresentação. Brasília, DF, 2014c. . Pacto nacional pela alfabetização na idade certa: organização do trabalho pedagógico. Brasília, DF, 2014 b.

. Pacto nacional pelo fortalecimento do ensino médio: documento orientador das ações de formação continuada de professores e coordenadores pedagógicos do Ensino Médio em 2014. Brasília, DF, 2014a.

COSTA, M. V. O magistério na política cultural: identidade, discurso e poder. In: COSTA, M. V. (Org.). O magistério na politica cultural. Canoas: Ulbra, 2006.

FOCAULT, M. A ordem do discurso: aula inaugural no College de France, pronunciada em 2 de dezembo de 1970. São Paulo: Loyola, 1996.

GARCIA, M. M. A. Identidade docente. In: OLIVEIRA, D. A.; DUARTE, A. M. C.; VIEIRA, L. M. F. Dicionário: trabalho, profissão e condição docente. Belo Horizonte: Faculdade de Educação UFMG, 2010. 
MAUÉS, O. C. A política da OCDE para a educação e a formação docente: a nova regulação? Educação (Porto Alegre), v. 34, n. 1, p. 75-85, jan./abr. 2011.

PIMENTA, S. G. A formação de professores para a Educação Infantil e para os anos iniciais do Ensino Fundamental: análise do currículo dos cursos de Pedagogia de instituições públicas e privadas do Estado de São Paulo. In: ENCONTRO NACIONAL DE DIDÁTICA E PRÁTICAS DE ENSINO - ENDIPE, 17., 2014, Fortaleza, CE. Anais... Fortaleza: UECE, 204. p. 1-18.

\section{Informações das autoras}

Patrícia de Faria Ferreira: Programa de Pós-Graduação em Ensino de Ciências e Matemática (PPGECM) da Universidade Federal de Pelotas (UFPel). Grupo de Estudos em Docência e Educação Básica (Gedeb). Contato: patriciafariaf@hotmail.com

Márcia Souza da Fonseca: Programa de Pós-Graduação em Educação Matemática (PPGEMAT), Programa de Pós-Graduação em Ensino de Ciências e Matemática (PPGECM), Universidade Federal de Pelotas (UFPel). Grupo de Estudos em Docência e Educação Básica (Gedeb). Contato: mszfonseca@gmail.com 